\title{
Adsorption of phosphate from aqueous solutions using waste mussel shell
}

\author{
Nur Atikah Abdul Salim ${ }^{1}$, Noorul Hudai Abdullah ${ }^{1}$, Muhammad Rijaluddin Khairuddin ${ }^{1}$, \\ Mohd A'ben Zulkarnain Rudie Arman', Mohd Hairul Khamidun², Mohamad Ali Fulazzaky3, \\ Abdull Rahim Mohd Yusoff ${ }^{4}$, Mohd Hafiz Dzarfan Othman ${ }^{5}$, and Mohd Hafiz Puteh ${ }^{1,1^{*}}$ \\ ${ }^{1}$ School of Civil Engineering, Universiti Teknologi Malaysia, 81310 Johor Bahru, Johor, Malaysia \\ ${ }^{2}$ Faculty of Civil and Environmental Engineering, Universiti Tun Hussein Onn, 86400 Batu Pahat, \\ Johor, Malaysia \\ ${ }^{3}$ Muhammadiyah University of Prof. Dr. Hamka, 12130 Jakarta, Indonesia \\ ${ }^{4}$ Ibnu Sina Institute for Scientific and Industrial Research, Universiti Teknologi Malaysia, 81310 Johor \\ Bahru, Johor, Malaysia \\ 5 Advanced Membrane Technology Research Centre (AMTEC), School of Chemical and Energy \\ Engineering, Universiti Teknologi Malaysia, 81310 Johor Bahru, Johor, Malaysia
}

\begin{abstract}
Excessive amount of phosphate released from wastewater can cause eutrophication to the receiving waters. Adsorption technique has been used to remove phosphate from aqueous solutions. The use of waste mussel shell (WMS) to remove phosphate from aqueous solutions and application of several kinetic and isotherm models to describe the adsorption of phosphate onto WMS were conducted in batch experiments. The phosphate adsorption by the WMS was examined with respect to solute concentration, contact time and adsorbent dose. The phosphate removal efficiencies obtained were $46.7,57.6,64.1,70.8$ and $75.2 \%$ at $144 \mathrm{~h}$ contact time for WMS dosage of 2, 4, 6, 8 and $10 \mathrm{~g}$, respectively. Physical and chemical properties of WMS including surface physical morphology and elemental compositions were characterized. A comparison of kinetic models applied to the phosphate adsorption onto WMS was evaluated for the pseudo-first order and pseudo-second order model. The experimental data fitted very well with the pseudo-second order kinetic model $\left(R^{2}>0.984\right)$, which indicated the adsorption process was chemisorption. In the isotherm studies, the Langmuir and Freundlich isotherm models were applied. The results indicated that the use of Freundlich equation is well described with the phosphate adsorptions onto WMS $\left(R^{2}=0.968\right)$, suggesting the heterogeneity of the adsorbent surface. The experimental results suggested the use of WMS as an excellent adsorption material for phosphate removal from aqueous solutions, giving new insights into environmental engineering practices.
\end{abstract}

\footnotetext{
* Corresponding author: mhafizputeh@utm.my
} 


\section{Introduction}

The excessive amount of phosphate release from domestic wastewater may lead to degradation of the receiving water, and thus cause eutrophication process [1]. When a water body is enriched with phosphate, it can stimulate the growth of plants and algal blooms making the water to lost its important function and induce adverse effects on human health and environment [2,3]. Malaysia has set a limit level of $5 \mathrm{mg} \mathrm{L}-1$ phosphorus in an enclosed water of body and $10 \mathrm{mg} \mathrm{L}-1$ of phosphorus released to rivers as an acceptable condition for effluent [4]. The Malaysian effluent standard has been permitted to release higher concentration of phosphorus into waters in comparison to the European Union (EU) and United State Environmental Protection Agency (USEPA) effluent standards. According to the EU, the limit values of phosphorus for effluent discharge in wastewater treatment plants are in a range of 1.0-2.0 mg L-1 [5]. The effluent limit of total phosphorus according to USEPA Clean Water Act is 0.5-0.8 mg L-1 [6].

The excessive amounts of phosphate in domestic wastewater must be treated with an appropriate method for instance adsorption process, chemical process and biological process $[7,8]$. Above all, adsorption is the most common yet potential techniques thats can be proposed to remove phosphate from domestic wastewater. This is because it has simple reaction, natural process, low-cost material and easy to handle [9]. The commonly used adsorbents are carbon, laterite, egg shells, crab shells and peat. The selection of waste mussel shell (WMS) as adsorbent is newly discovered and it is easily available in Malaysia, especially in Johor. Mussel is a freshwater habitats and lives in saltwater. The production of mussel habitat is many in coastal areas and WMS were normally dumped directly to the foreshore, roadside and garbage area as waste that can give adverse effect to the environment [10]. The use of WMS as an effective adsorbent material for the adsorption of phosphate from water has been proven [8]. Even though many adsorption models have been used to investigate adsorption performance, understanding on the kinetic and isotherm for adsorption of phosphate is crucial to be investigated. This is due to the limited understanding on phosphate adsorption by using WMS in aqueous solution. The objectives of this study are to understand the removal of phosphate from aqueous solution onto WMS and to verify the use of kinetic and isotherm study for adsorption of phosphate from aqueous solution onto WMS.

\section{Materials and methods}

\subsection{Materials}

The WMS samples were collected from foreshore in Pasir Gudang, Johor, Malaysia. The samples were cleaned with tap water and dried at $30^{\circ} \mathrm{C}$ for 2 days in an oven $[11,12]$. The dried samples were crushed with mixer grinder (Panasonic, Model MX-AC400W, Malaysia) and sieved to $0.6-1.18 \mathrm{~mm}$. Surface morphology of WMS was examined via scanning electron microscopy (SEM) and elemental composition of WMS was determined using Xray diffraction (EDX) instrument [8]. The synthetic solution with concentration of $100 \mathrm{mg} \mathrm{L}^{-}$ ${ }^{1}$ of $\mathrm{PO}_{4}{ }^{3-}$ was prepared by dissolving $0.1433 \mathrm{~g}$ of potassium dihydrogen phosphate $\left(\mathrm{KH}_{2} \mathrm{PO}_{4}\right)$ (analytical grade) into $1 \mathrm{~L}$ of deionised water in a volumetric flask [13]. The synthetic solution was diluted with deionised water when necessary. 


\subsection{Adsorption experiments}

Adsorption kinetic and isotherm studies were conducted at $25^{\circ} \mathrm{C}$ with the initial concentration of the synthetic phosphate solution of $5 \mathrm{mg} \mathrm{PO}_{4}{ }^{3-} \mathrm{L}^{-1}$. The adsorption kinetic experiment was performed in $100 \mathrm{~mL}$ of phosphate solution in Erlenmeyer flask loaded with different mass of adsorbent which are 2, 6 and $10 \mathrm{~g}$ of WMS and continually shaken at $140 \mathrm{rpm}$ for 144 hours. In the adsorption isotherm study, 2, 4, 6, 8 and $10 \mathrm{~g} \mathrm{WMS}$ adsorbent were loaded in $100 \mathrm{~mL}$ of phosphate synthetic solution in Erlenmeyer flask and shaken at $140 \mathrm{rpm}$ for 144 hours. The samples were taken from the flask at certain time interval and centrifuged for 10 min at $6000 \mathrm{rpm}$ using EBA 21 Hettich centrifuge. The supernatant was subsequently analysed for phosphate concentration, $\mathrm{pH}$ and temperature. Phosphate concentration was analysed according to the Amino Acid Method using HACH DR6000 UVSpectrophotometer [14].

Equation 1 and 2 were used to compute the value of adsorption capacity $(q)$ and removal efficiency $(E)$, respectively. The adsorption capacity and removal efficiency equations [10] are expressed as:

$$
q=\frac{\left(C_{i}-C_{f}\right) x V}{m}
$$

where $q$ is the adsorption capacity $\left(\mathrm{mg} \mathrm{g}^{-1}\right), C_{i}$ is the initial phosphate concentration $\left(\mathrm{mg} \mathrm{L}^{-1}\right)$ , $\mathrm{C}_{\mathrm{f}}$ is the phosphate concentration in the solution $\left(\mathrm{mg} \mathrm{L}^{-1}\right), m$ is the mass of adsorbent $(\mathrm{g})$ and $V$ is the volume of solution (L).

$$
E=\frac{C_{i}-C_{f}}{C_{i}} \times 100 \%
$$

where $E$ is the removal efficiency (\%), $C_{i}$ is the initial phosphate concentration $\left(\mathrm{mg} \mathrm{L}^{-1}\right)$ and $C_{f}$ is the concentration of phosphate in the solution $\left(\mathrm{mg} \mathrm{L}^{-1}\right)$.

\section{Results and discussion}

\subsection{Waste mussel shell characterization}

The surface morphology of WMS was performed using scanning electron microscopy (SEM, Hitachi, Model TM3000, Japan). Fig.1 shows SEM photographs of WMS with 500, 1500 and 6000 times magnification. Fig. 1a shows that the SEM image of 500 times had a compact texture. The SEM micrograph image with 1,500 times magnification (Fig. 1b) and 6,000 times magnification (Fig. 1c) exhibit a rough surface with small pores.

The elemental composition analysis of WMS was examined by EDX (Energy-Dispersive X-Ray Spectroscopy, Bruker, Model X Flash 6I10, German). Table 1 shows the cationic compositions of WMS. The major cationic compositions were identified as $\mathrm{Ca}(34.61 \%)$ and $\mathrm{Na}(1.26 \%)$ while the minor cationic compositions were $\mathrm{Fe}(0.2 \%)$ and $\mathrm{Al}(0.08 \%)$.

Table 1. Elemental composition of the WMS (wt.\%) by EDX.

\begin{tabular}{llll}
\hline $\mathbf{C a}$ & $\mathbf{N a}$ & $\mathbf{F e}$ & $\mathbf{A l}$ \\
\hline 34.61 & 1.26 & 0.2 & 0.08 \\
\hline
\end{tabular}


(a)

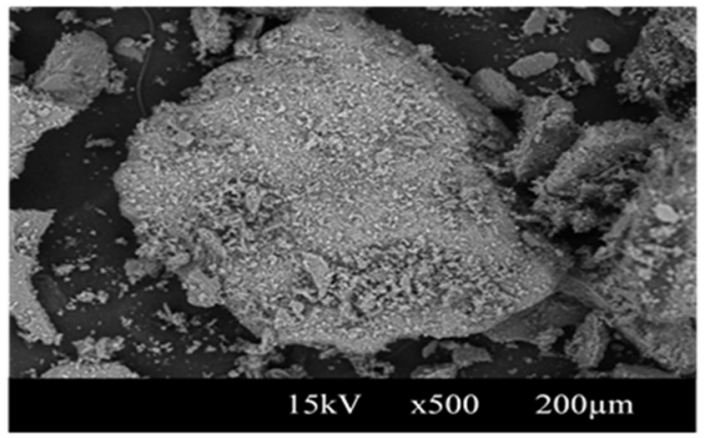

(b)

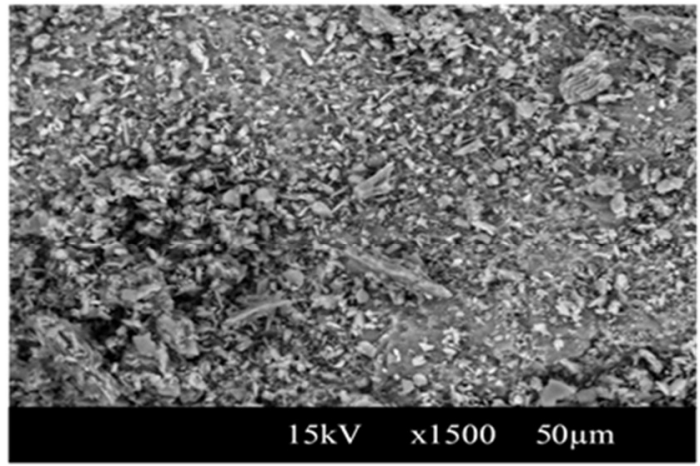

(c)

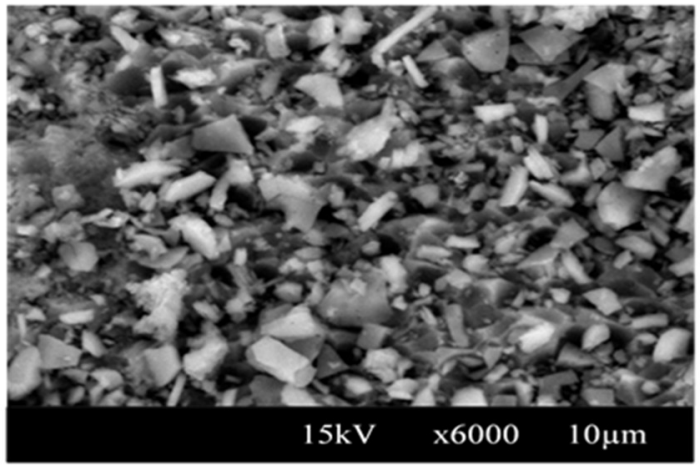

Fig. 1. SEM photomicrograph of WMS: (a) 500 times magnifications (b) 1500 times magnifications (c) 6000 times magnifications.

\subsection{Adsorption of phosphate}

The phosphate removal efficiencies, $E$ were $46.7,64.1$ and $75.2 \%$ at 144 h contact time for the WMS dosage of 2, 6 and $10 \mathrm{~g}$, respectively; as shown in Fig. 2. The adsorption process could be due to the electrostatic interaction. The affinity between calcium oxide presented on the WMS surface and phosphate ions is quite strong because both compounds have different charges that may cause attractive effect on each other [15]. The removal efficiency to adsorb phosphate onto WMS rapidly increases during the first $1.5,3.5$ and $7 \mathrm{~h}$ of contact time for WMS dosage of 2, 6 and $10 \mathrm{~g}$, respectively, and continue to increase slowly until it reached an equilibrium level. Therefore, the equilibrium times were 144, 144, and $120 \mathrm{~h}$ for the adsorptions of phosphate onto WMS with the amounts of 2, 6, $10 \mathrm{~g}$, respectively. The rapid increase in the adsorption of phosphate onto WMS from a synthetic solution may be due to 
the adsorbent surface that contains high number of active sites [16]. Similar results have been reported for the adsorption of phosphate from aqueous solution onto a calcined waste eggshell [2] and a modified wheat residue [17].

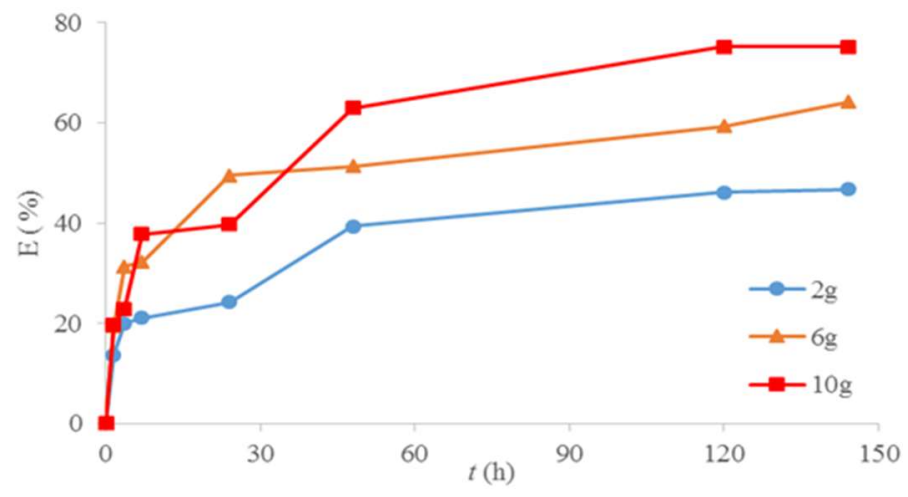

Fig. 2. Variation of removal efficiency for the adsorption of phosphate onto WMS from a synthetic solution.

The effects of different amount of WMS $(m)$ on both $E$ and $q$ for phosphate adsorption were observed using 2, 4, 6, 8 and $10 \mathrm{~g}$ WMS as shown in Fig. 3. The figure (Fig. 3a, b) shows that $E$ for adsorption of phosphate increases from 46.7 to $75.2 \%$ but $q$ decreases from 0.11 to $0.03 \mathrm{mg} \mathrm{g}^{-1}$ with the increasing amounts of WMS from 2 to $10 \mathrm{~g}$. The increase in $E$ could be due to the increased in the WMS amount which may increase its surface area and number of active sites to having more possibility of adsorbing more phosphate from a synthetic solution [18]. The decreased value of $q$ with increasing amount of WMS is due to the adsorption active sites remaining unsaturated during the adsorption process. Therefore, the use of more WMS could be difficult to achieve at a saturation level [16]. A similar result has been reported for the adsorption of phosphate onto calcined mussel shells to show that the value of $E$ increases with the increasing amount of adsorbent [8]. 


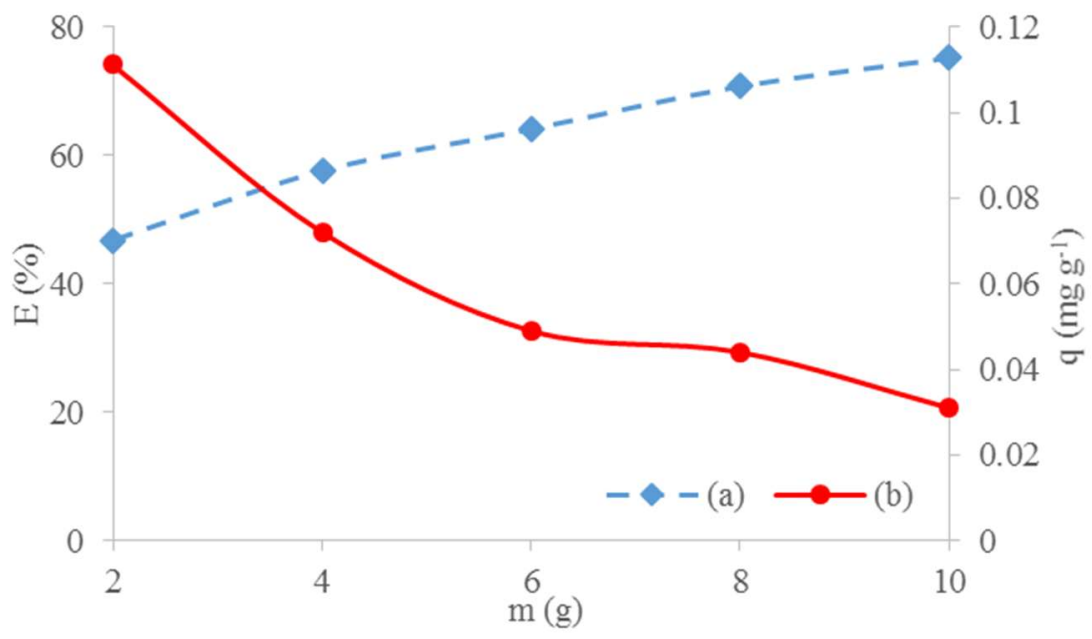

Fig. 3. Relationship of: (dashed line) the removal efficiency and the amount of WMS; (solid line) the adsorption capacity and the amount of WMS; (a) $E$ for the adsorption of phosphate and (b) $q$ for the adsorption of phosphate.

\subsection{Adsorption kinetics}

The experimental data were applied to the pseudo-first-order and pseudo-second-order equations in order to evaluate the adsorption kinetics of phosphate onto WMS [10]. The pseudo-first-order equation [9] is expressed as:

$$
\ln \left(q_{e}-q_{t}\right)=\ln \left(q_{e}\right)-k_{1} t_{i}
$$

where $q_{e}$ is the equilibrium amount of phosphate adsorbed $\left(\mathrm{mg} \mathrm{g}^{-1}\right), q_{t}$ is the amount of phosphate adsorbed at adsorption time ( $\left.\mathrm{mg} \mathrm{g}^{-1}\right), k_{l}$ is a rate constant of pseudo-first-order equation $\left(\mathrm{min}^{-1}\right)$ and $t_{i}$ is the adsorption time (min). The value of $k_{l}$ and $\ln q_{e}$ can be evaluated from the slope and intercept of plot $\ln \left(q_{e}-q_{t}\right)$ versus $t_{i}$, respectively as shown in Fig. 4a. The adsorption kinetic follows a pseudo-first-order model when the plot of $\ln \left(q_{e}-q_{t}\right)$ versus $t_{i}$ gives a straight line [19]. The pseudo-second-order equation [2] is expressed as:

$$
\frac{t_{i}}{q_{t}}=\frac{1}{k_{2} q_{e}^{2}}+\frac{t_{i}}{q_{e}}
$$

where $q_{t}\left(\mathrm{mg} \mathrm{g}^{-1}\right)$ is the amount of phosphate adsorbed at adsorption time, $q_{e}$ is the amount of phosphate adsorbed at equilibrium time ( $\left.\mathrm{mg} \mathrm{g}^{-1}\right), k_{2}$ is a rate constant of pseudo-secondorder model $\left(\mathrm{min}^{-1}\right)$ and $t_{i}$ is the adsorption time $(\mathrm{min})$. The value of $k_{2}$ and $q_{e}$ can be evaluated from the intercept and slope of plot $t_{i} / q_{t}$ versus $t_{i}$ as shown in Fig. $4 \mathrm{~b}$. The adsorption kinetic follows a pseudo-second-order model when the plot of $t_{i} / q_{t}$ versus $t_{i}$ gives a straight line [2]. These two adsorption kinetic models have been applied for the phosphate adsorption from aqueous solution $[2,8,16]$. The kinetic parameters $k_{1}, k_{2}$ and $q_{e}$ for these two adsorption kinetic models are shown in Table 2. 
The error function $\left(F_{\mathrm{e}}\right)$ equation [20] is expressed as:

$$
F_{e}=\sqrt{\left(\frac{1}{n-p}\right) \cdot \sum_{i}^{n}\left(q_{t(\exp )}-q_{t(\text { theo })}\right)^{2}}
$$

where the value of $q_{\mathrm{t}(\exp )}\left(\mathrm{mg} \mathrm{g}^{-1}\right)$ can be calculated by using Equation 1 and the value of $q_{\mathrm{t} \text { (theo) }}\left(\mathrm{mg} \mathrm{g}^{-1}\right)$ can be calculated by using Equation 3 or $4, p$ and $n$ are the number of parameters in the kinetic equation and number of measurements, respectively. The most suitable kinetic model either pseudo-first-order or pseudo-second-order should have the highest correlation coefficient $\left(R^{2}\right)$ and the lowest $F_{\mathrm{e}}$ value.

(a)

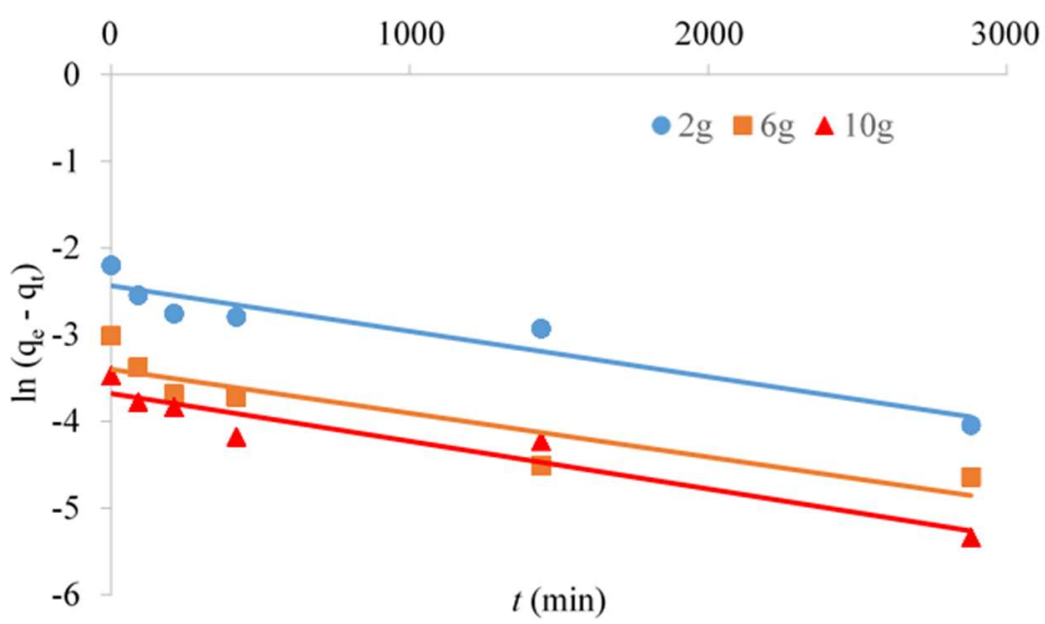

(b)

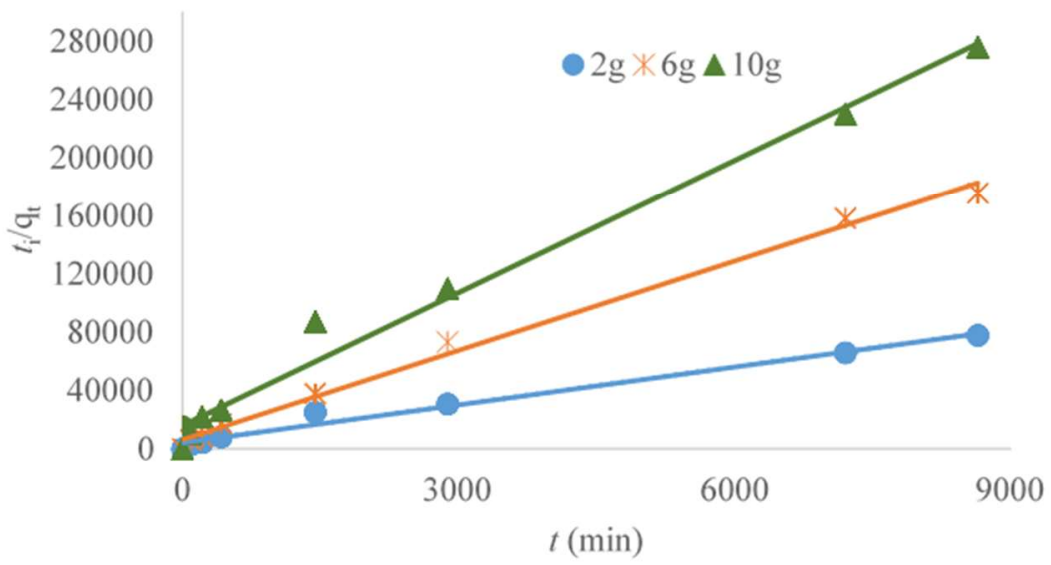

Fig. 4. Linear regression analysis for (a) pseudo-first-order model and (b) pseudo-second-order model for the adsorption of phosphate onto WMS from a synthetic solution. 
Table 2. Kinetic parameters for the adsorption of phosphate onto WMS.

\begin{tabular}{|c|c|c|c|c|c|c|}
\hline \multirow[b]{2}{*}{ Sample } & \multirow{2}{*}{$\begin{array}{c}\text { Amount } \\
(\mathrm{g})\end{array}$} & \multicolumn{3}{|c|}{ Pseudo-first-order model } & \multirow[b]{2}{*}{$F_{e}$} & \multirow[b]{2}{*}{$\begin{array}{c}q_{e(\exp )} \\
\left(\mathrm{mg} \mathrm{g}^{-1}\right)\end{array}$} \\
\hline & & $\begin{array}{c}q_{e(\text { theo })} \\
\left(\mathrm{mg} \mathrm{g}^{-1}\right)\end{array}$ & $\begin{array}{c}k_{l} \\
\left(\min ^{-1}\right)\end{array}$ & $R^{2}$ & & \\
\hline \multirow[t]{3}{*}{ Synthetic solution } & 2 & 0.087 & 0.0005 & 0.896 & 0.0118 & 0.111 \\
\hline & 6 & 0.033 & 0.0005 & 0.807 & 0.0078 & 0.049 \\
\hline & 10 & 0.025 & 0.0006 & 0.914 & 0.0029 & 0.031 \\
\hline \multirow[b]{2}{*}{ Sample } & Amount & \multicolumn{3}{|c|}{ Pseudo-second-order model } & & \\
\hline & (g) & $\begin{array}{c}\text { qe(theo) } \\
\left(\mathrm{mg} \mathrm{g}^{-1}\right)\end{array}$ & $\begin{array}{c}k_{2} \\
\left(\mathrm{~g} \mathrm{mg}^{-1}\right. \\
\left.\mathrm{min}^{-1}\right)\end{array}$ & $R^{2}$ & $F_{e}$ & $\begin{array}{c}q_{e(\exp )} \\
\left(\mathrm{mg} \mathrm{g}^{-1}\right)\end{array}$ \\
\hline \multirow[t]{3}{*}{ Synthetic solution } & 2 & 0.116 & 0.0173 & 0.984 & 0.0019 & 0.111 \\
\hline & 6 & 0.049 & 0.0663 & 0.994 & 0 & 0.049 \\
\hline & 10 & 0.033 & 0.0570 & 0.985 & 0.0008 & 0.031 \\
\hline
\end{tabular}

As shown in Table 2, the correlation coefficient $\left(R^{2}>0.984\right)$ for pseudo-second-order model was higher than that $\left(R^{2}>0.807\right)$ for pseudo-first-order model. The results indicate that pseudo-second-order-kinetic model is well described with the adsorption kinetic of phosphate onto WMS from a synthetic solution compared to pseudo-first-order model because higher value of $R^{2}$ and lower value of $F_{e}$ have been verified. These results imply that the adsorption between adsorbent-adsorbate can be classified mainly as chemisorption mechanism which is due to the adsorption process that involves the sharing of electrons between adsorbent and adsorbate resulting into a chemical bond [21].

\subsection{Adsorption isotherm}

The experimental data were applied to the Langmuir and Freundlich isotherm equations [8]. The Freundlich equation [7] is expressed as:

$$
\ln q_{e}=\ln K_{F}+\frac{1}{n} \ln C_{e}
$$

where $q_{e}$ is the equilibrium amount of phosphate adsorbed $\left(\mathrm{mg} \mathrm{g}^{-1}\right), K_{F}$ is the Freundlich constant ( $\left.\mathrm{mg} \mathrm{g}^{-1}\right), n$ (dimensionless) is the heterogeneity factor should has a lower value for more heterogeneous surfaces and $C_{\mathrm{e}}$ is the equilibrium concentration $\left(\mathrm{mg} \mathrm{L}^{-1}\right)$. The Langmuir equation [10] is represented as:

$$
\frac{1}{q_{e}}=\frac{1}{K_{L} q_{\max } C_{e}}+\frac{1}{q_{\max }}
$$

where $q_{\mathrm{e}}$ is the equilibrium amount of phosphate adsorbed $\left(\mathrm{mg} \mathrm{g}^{-1}\right), q_{\max }$ is the maximum adsorption capacity $\left(\mathrm{mg} \mathrm{g}^{-1}\right), K_{\mathrm{L}}$ is the adsorption energy constant $\left(\mathrm{L} \mathrm{mg}^{-1}\right)$ and $C_{\mathrm{e}}$ is the equilibrium concentration $\left(\mathrm{mg} \mathrm{L}^{-1}\right)$. The significant of adsorption isotherm is to determine the capacity of adsorbents for adsorbing pollutants and in giving a viewpoint of the functional dependence of capacity on the concentration of pollutant in an aqueous solution.

The value of $K_{\mathrm{F}}$ and $n$ can be calculated from intercept and slope of plot $\ln \left(q_{\mathrm{e}}\right)$ versus $\ln \left(C_{\mathrm{e}}\right)$ as shown in Fig. 5a while the Langmuir parameters $K_{L}$ and $q_{\max }$ were calculated from slope and intercept of plot $1 / q_{\mathrm{e}}$ versus $1 / C_{\mathrm{e}}$ as shown in Fig. $5 \mathrm{~b}$. All the values of the parameters calculated using these two isotherm models are listed in Table 3. Correlation for all the parameters in Freundlich and Langmuir equations is very good $\left(R^{2}>0.96\right)$, suggesting that the use of these parameters can be used to explain the adsorption phenomena for the 
removal of phosphate from synthetic solution by adsorbing onto WMS [8]. As compared with the Langmuir equation, the Freundlich equation is fitted better with $R^{2}=0.968$. This suggests the heterogeneity of the adsorbent surface [22]. The $1 / n$ value of 0.908 was verified for the adsorption of phosphate onto WMS from synthetic solution (Table 3 ). The $1 / \mathrm{n}$ value lie between $0.1<1 / \mathrm{n}<1$, indicates a favourable adsorption [23]. This result implies that active sites with the highest binding energies would be used first for less heterogeneous surfaces and then pursued by weaker sites for more heterogeneous surfaces [24].

Table 3. Freundlich and Langmuir isotherm constants.

\begin{tabular}{lccccccc}
\hline \multirow{3}{*}{ Sample } & \multicolumn{9}{c}{ Freundlich model } & \multicolumn{3}{c}{ Langmuir model } & \multirow{2}{*}{$R^{2}$} \\
\cline { 2 - 6 } & $n$ & $1 / n$ & $\begin{array}{c}K_{F} \\
\left(\mathrm{mg} \mathrm{g}^{-1}\right)\end{array}$ & $R^{2}$ & $\begin{array}{c}q_{\max } \\
\left(\mathrm{mg} \mathrm{g}^{-1}\right)\end{array}$ & $\begin{array}{c}K_{L} \\
\left(\mathrm{~L} \mathrm{mg}^{-1}\right)\end{array}$ & \\
\hline $\begin{array}{l}\text { Synthetic } \\
\text { solution }\end{array}$ & 1.101 & 0.908 & 0.027 & 0.968 & 0.825 & 0.032 & 0.965 \\
\hline
\end{tabular}

(a)

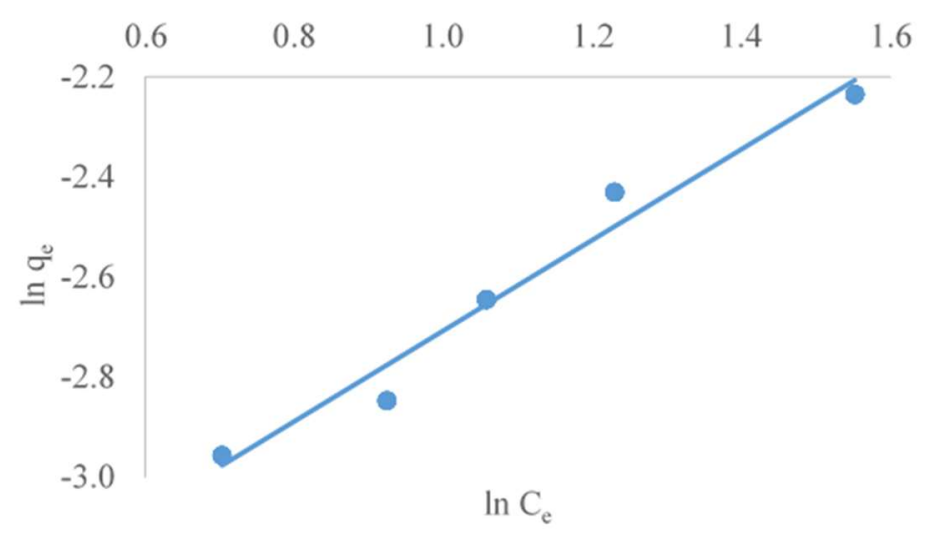

(b)

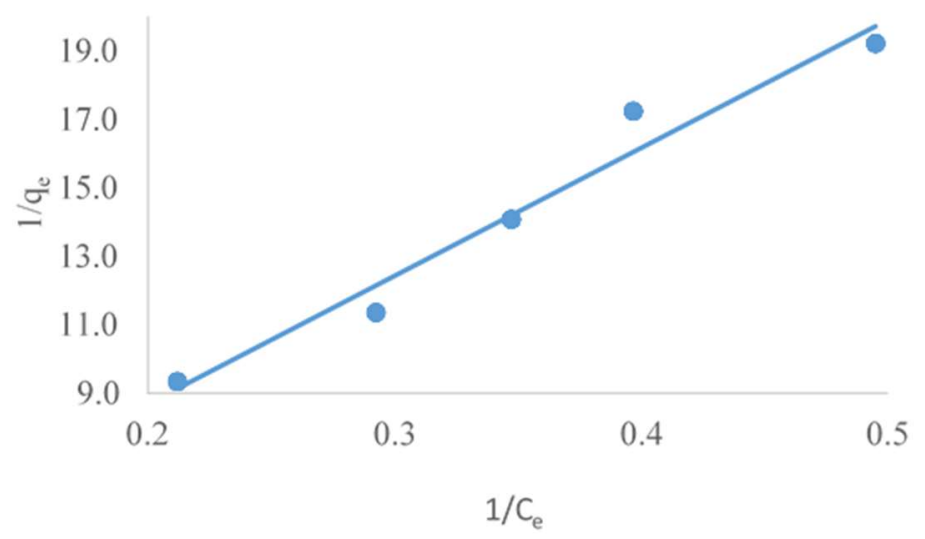

Fig. 5. Linear line of plotting (a) $l_{n}\left(q_{\mathrm{e}}\right)$ versus $\ln \left(C_{\mathrm{e}}\right)$ and (b) $1 / q_{\mathrm{e}}$ versus $1 / C_{\mathrm{e}}$ for the adsorption of phosphate onto WMS from synthetic solution. 


\section{Conclusions}

In this work, application of the kinetic and isotherm models has been successfully conducted to describe the mechanism of phosphate adsorption from synthetic solution onto WMS. The application of pseudo-second-order models has best described the adsorption kinetic data $\left(R^{2}\right.$ $>0.984$ ), indicating that chemical adsorption (chemisorption) would be involved during the adsorption process. The adsorption of phosphate onto WMS was best described by Freundlich models $\left(R^{2}=0.968\right)$, indicating that the heterogeneity of the adsorbent surface. The maximum adsorption capacity was estimated to be $0.825 \mathrm{mg} \mathrm{g}^{-1}$. The result findings can provide useful information for the adsorption mechanism and the selection of WMS as an effective adsorbent material for the removal of phosphate from synthetic solution.

The authors would like to thank the Universiti Teknologi Malaysia (UTM) and Ministry of Higher Education (MOHE) for financial support of Fundamental Research Grant Scheme (Vot. No. 4F956).

\section{References}

1. M. A. Fulazzaky, N. H. Abdullah, A. R. Mohd Yusoff, E. Paul, J. Clean. Prod. 3, 1-7 (2015)

2. T. E. Köse, B. Kivanç, Chem. Eng. J. 178, 34-39 (2011)

3. M. A. Fulazzaky, N. A. A. Salim, N. H. Abdullah, A. R. Mohd Yusoff, E. Paul, Chem. Eng. J. 253, 291-297 (2014)

4. DOE. Environmental Requirements: A Guide for Investor. Putrajaya (2010)

5. Commission of the European Communities. Council Directive Concerning Urban Waste-water Treatment. 91/271/EEC (1991)

6. A. H. Caravelli, E. M. Contreras, N. E. Zaritzky, J. Hazard. Mater. 177(1-3), 199-208 (2010)

7. M. A. Fulazzaky, M. H. Khamidun, M. F. M. Din, A. R. M. Yusoff, Chem. Eng. J. 258, 10-17 (2014)

8. J. Xiong, Y. Qin, E. Islam, M. Yue, W. Wang, Desalination. 276, 1-3, 317-321 (2011)

9. E. Worch, Adsorption technology in water treatment: Fundamentals, processes, and modeling (Walter de Gruyter, Germany, 2012)

10. Chen, Y. Cai, M. Clark, Yu, PLoS ONE. 8(4), 1-10 (2013)

11. W. Lee, H. B. Kwon, H. P. Jeon, B. Koopman, J Clean Prod. 17(7):683-87 (2009)

12. Abeynaike, L. Wang, M. I. Jones, D. A. Patterson, Asia-Pac. J. Chem. Eng. 6, 231-243 (2011)

13. M. Zapater-Pereyra, E. Malloci, J. J. A.van Bruggen, P. N. L. Lens, Ecol. Eng. 73, 635642 (2014)

14. American Public Health Association, APHA. Standard Methods for The Examination of Water and Wastewater. Washington, D.C: APHA. (21th Edition) (2009)

15. K. Karageorgiou, M. Paschalis, G. N. Anastassakis, J. Hazard. Mater. 139(3), 447-452 (2007)

16. H. Aydın, Y. Bulut, J. Environ. Manage. 87, 37-45 (2008)

17. X. Xu, B. Gao, W. Wang, Q. Yue, Y. Wang, S. Ni, Colloids Surf. B: Biointerfaces 70(1), 46-52 (2009)

18. Romar-Gasalla, I. M. Rivas-Pérez, R. Paradelo-Núñez, J. C. Nóvoa-Muñoz, M. AriasEstévez, M. J. Fernández-Sanjurjo, A. Núñez-Delgado, Geoderma. 280, 8-13 (2016)

19. M.Y. Liu, D.C. Tsang, J. Hu, K.T. Ng, T. Liu, I.M. Lo, J. Environ. Eng. 134, 338-345 (2008) 
20. M.C. Ribas, M.A. Adebayo, L.D.T. Prola, Lima, E.C. R. Cataluña, L. Feris, M.J. Puchana-Rosero, F.M. Machado, F.A. Pavan, T. Calvete, Chem. Eng. J. 248, 315-326 (2014)

21. Ali, M. Asim, T. A. Khan, J. Environ. Manage. 113, 170-183 (2012)

22. W. Y. Huang, R. H. Zhu, F. He, D. Li, Y. Zhu, Y. M. Zhang, Chem. Eng. J. 228, 679687 (2013)

23. E. Marañón, M. Ulmanu, Y. Fernández, I. Anger, L. Castrillón, J. Hazard. Mater. B. 137(3), 1402-1409 (2006)

24. E. M. Ö. Kaya, A. S. Özcan, Ö. Gök, A. Özcan, Adsorpt. 19(2-4), 879-888 (2013) 